\title{
A expansão da educação superior pública e suas implicações no trabalho docente
}

\author{
Carla Vaz dos Santos Ribeiro \\ Denise Bessa Leda \\ Universidade Federal do Maranhão \\ Eduardo Pinto e Silva \\ Universidade Federal de São Carlos
}

\section{Resumo}

Oartigo tem como objetivo analisar a expansão da educação superior pública e suas implicações no trabalho docente. Apresenta dados que se integram ao tema "Trabalho Docente e Expansão da Educação Superior", relativos a três eixos de demanda multiforme da intensificação do trabalho: EaD; Pós-Graduação e Graduação. As pesquisas apresentadas utilizaram, como instrumentos de coleta de dados questionários e entrevistas, que foram analisados à luz do materialismo histórico-dialético. Considera-se que a intensificação do trabalho e a sociabilidade produtiva englobam, de forma contraditória, prazer, sofrimento e defesas patogênicas, assim como adoecimento permeado por dimensões afetivas, éticas e políticas.

Palavras-chave: Expansão da educação superior pública. Trabalho do professor. Subjetividade.

\section{The expansion of public higher education and its implications in teaching work}

\begin{abstract}
${ }^{1}$
This article aims to examine the expansion of public higher education and its implications for teachers' work. It presents data from researches integrated around the theme "Teaching Work and Expansion of Higher Education", which are related to three axes characterizing the multiform demand of work intensification: Distance Education, Graduation and Undergraduate Program. The researches analyzed questionnaires and interviews in the light of the historical and dialectic materialism. It is considered that the intensification of work and the productive sociability encompass, in a contradictory way, pleasure, suffering and pathogenic defenses, as well as illness permeated by affective, ethical and political dimensions.

Keywords: Expansion of public higher education. Teachers work. Subjectivity.
\end{abstract}




\section{La expansión de la educación superior estatal y sus consecuencias en la docencia}

\section{Resumen $^{2}$}

Este artículo tiene como objetivo analizar la expansión de la educación superior estatal y sus consecuencias en la docencia. Presenta datos integrados al tema "Trabajo Docente y Expansión de la Educación Superior", cubriendo tres áreas de demanda multiforme de intensificación del trabajo: EAD; Posgrado; Graduación. Las investigaciones presentadas emplearon cuestionarios y entrevistas, examinados a la luz del materialismo histórico dialéctico. Se considera que la intensificación docente y sociabilidad productiva, contradictoriamente, engloban placer, sufrimiento, defensas patógenas y también la enfermedad impregnada por dimensiones afectivas, éticas y políticas.

Palabras-claves: Expansión de la educación superior estatal. Trabajo del profesor. Subjetividad.

\section{Introdução}

No presente artigo, procura-se analisar a expansão da educação superior pública, com ênfase nas universidades federais, abrangendo seus campi matriciais e do interior, e suas repercussões no trabalho do professor. As configurações da expansão da educação superior, em suas distintas frentes - Educação a Distância (EaD), Pós-Graduação, Graduação - são abordadas por estudos do grupo de pesquisa "Trabalho Docente na Expansão da Educação Superior ${ }^{3} . "$

Dados dessas pesquisas foram apresentados e discutidos no XXII Seminário Nacional Universitas/Br, realizado em maio de 2014, na Universidade Federal do Rio Grande do Norte (UFRN). Neste texto, houve a preocupação em retomar as sistematizações e discussões realizadas na mesa redonda "Trabalho Docente na Expansão da Educação Superior", procurando destacar as implicações de uma expansão tão contraditória quanto desordenada e multifacetada da educação superior brasileira, na subjetividade e saúde do professor. 
trabalho do professor universitário, eixo orientador de todos os estudos de nosso grupo de pesquisa, é compreendido como atividade humana fundamental, constitutiva de uma relação indissociável entre sociabilidade e subjetividade, em que pese a irredutibilidade de uma a outra. Sociabilidade que assume determinadas feições predominantes no contexto de uma expansão universitária prenhe de valores instrumentais e de naturalização das práticas gerencialistas que assolam tanto o Estado como as práticas sociais e institucionais mais diversas. Torna-se importante ressaltar que, ao analisar a categoria subjetividade, é necessário levar em consideração que: "[...] um tratamento dialético e crítico da subjetividade pressupõe apreendê-la no interior de uma totalidade concreta histórico-social. Aliás, ela é parte constitutiva e constituinte desta totalidade social" (ALVES, 2006, p. 23).

Compreende-se que a subjetividade docente "[...] refere-se aos aspectos do pensamento, da vontade, das emoções, dos valores, da linguagem, dos aspectos desejantes e das práticas (comportamento) do professor", e que como a subjetividade de qualquer outro trabalhador, constitui-se na relação com a objetividade. Deste modo, entende-se que, para a sua análise, sejam superadas as intervenções "[...] que se perdem em leituras individualizantes, as quais abstraem os indivíduos de seu contexto e terminam por responsabilizá-los, individualmente, pelo sucesso ou fracasso de seu trabalho [...]."Portanto, a produção da subjetividade é necessariamente social e histórica IMANCEBO, 2010 , p. 3521 .

Nesse sentido, as pesquisas realizadas, ainda que, com distintos focos sobre a modalidade do trabalho do professor (EAD, pós-graduação e graduação) apontam, grosso modo, de forma similar, um aspecto central: o da racionalidade instrumental, pragmática e gerencialista da "nova universidade", vista como eficaz, inclusiva e democratizante pelos seus defensores, e geradora de trabalho intensificado e precarizado, pelos seus críticos. Outros pontos comuns que as pesquisas sinalizam são: as contradições da expansão da educação superior no Brasil; as distintas formas históricas do desenvolvimento das diferentes instituições e campi; as variações em termos do grau de intensificação e precarização e as díspares condições materiais e objetivas para plena realização das atividades de ensino, pesquisa e extensão. Cabe explicitar que essas desigualdades e variações se relacionam às próprias características das reconfigurações da economia e da política, isto é, da mundialização e 
A expansão da educação superior pública e suas implicações no trabalho docente

financeirização da economia (CHESNAIS, 1996) e do Estado reformado e com fortes traços mercantis (SGUISSARDI; SILVA JÚNIOR, 2009).

Neste artigo, retomam-se esses aspectos com uma indagação bastante pertinente: Como fica a subjetividade e a saúde do professor, assim como sua condição de ser político, histórico e desejante, inserido numa forma predominante de sociabilidade produtiva potencialmente avassaladora e reificadora?

Para discussão neste texto, serão priorizados os seguintes eixos: a expansão da educação superior no contexto de reconfiguração do Estado; as pesquisas do grupo trabalho docente na expansão da educação superior e, por fim, alguns elementos sobre o trabalho e a subjetividade do professor.

As pesquisas apresentadas, ao longo deste texto, utilizaram, como instrumentos de coleta de dados, questionários e entrevistas, analisados à luz do materialismo histórico-dialético. Para isso, tratou-se de ultrapassar os limites do imediatamente presente nas manifestações fenomênicas para buscar as raízes da conjuntura que as produziu, que, por sua vez, não são prontamente observáveis.

\section{As instituições públicas de educação superior no contexto de reconfiguração do estado}

A universidade pode ser tomada como uma das pouquíssimas instituições sociais que perdura ao longo dos séculos, em função de haver adotado o princípio de reforma permanente desde suas origens, seja por motivos próprios, ou por grandes mudanças econômicas, políticas e culturais que, eventualmente, a obrigaram a reinventar-se. Contudo, nenhuma mudança teria deixado marcas tão indeléveis na identidade da universidade, como as reformas que estão em curso a partir dos meados dos anos 1970, quando se inicia a crise do Estado do Bem-Estar Social. Essas instituições:

[...] desde então tendem a caracterizar-se por traços e marcas muito semelhantes, em que pesem o valor extremamente diferenciado de suas economias e a história de constituição de seus respectivos subsistemas de educação superior e universitário (SGUISSARDI; GOERGEN; DIAS SOBRINHO; PINO; PIOZZI; OLIVEIRA; CAMARGO, 2004, p. 648). 
Em razão da crise do Estado Bem-estar Social, ocorreram significativas transformações que afetaram os serviços públicos de modo geral influenciando, profundamente, as políticas, os programas, as estruturas e a cultura das organizações estatais (CHANLAT, 2002), tais como, escolas, centros de pesquisa, hospitais, museus e, inclusive, o nosso campo de investigação, as universidades públicas.

Essa crise cedeu lugar a um movimento reformista que tem, como proposta básica, a substituição do modelo burocrático pelo gerencial. $\bigcirc$ sentimento antiburocrático presente em boa parte da opinião pública, fruto de uma construção histórica, aponta o modelo de gestão do setor privado como o ideal. O Estado passa a conviver com a gradativa incorporação da lógica e dos mecanismos que regem o mundo das empresas privadas, com o objetivo de propiciar agilidade, eficiência e qualidade aos serviços.

$\bigcirc$ movimento em questão, conhecido como gerencialismo, disseminou-se em vários países do mundo e guarda uma estreita relação nas suas ações e valores com a reestruturação produtiva do pós-fordismo (PAULA, 2005). De acordo com Chanlat (2002), o gerencialismo assenta-se na premissa de que é possível explicar e interpretar o mundo a partir das categorias da gestão privada, lançando mão de noções e princípios administrativos, tais como: eficácia, produtividade, perfomance, competência, empreendedorismo, qualidade total, cliente, produto, marketing, desempenho, excelência e reengenharia.

Esses princípios do gerencialismo ganharam tamanho vulto e estão, cada vez mais, entrelaçados no tecido social. A sociedade se mobiliza a serviço da economia - a família é encarregada de produzir indivíduos autônomos e empregáveis e a educação deve satisfazer às necessidades do mercado. $\bigcirc$ homem deve transformar-se em um capital sempre mais produtivo e rentável. "Todos os aspectos da existência humana são apreendidos no registro da gestão. Da infância à aposentadoria, a gestão de si mesmo torna-se uma necessidade para se integrar" (GAULEJAC, 2007, p. 311 ).

A crescente presença do viés ideológico, exercido pelo gerencialismo, transformou a figura do gerente em uma das figuras centrais da sociedade contemporânea. $\bigcirc$ uso das palavras gestão, management, gerir e manager é tão comum a ponto de as pessoas não expressarem mais suas emoções, e sim gerenciá-las (CHANLAT, 1999, 2002). 
A expansão da educação superior pública e suas implicações no trabalho docente

No Brasil, o processo de reconfiguração do Estado, calcado na lógica gerencialista, ganhou força com a indicação de Bresser-Pereira para assumir - Ministério da Administração e Reforma do Estado (MARE), no governo de Fernando Henrique Cardoso, em 1995. Nesse período, foi apresentado o Plano Diretor da Reforma do Estado, dando início à implantação do modelo de administração pública gerencial.

A Reforma visava tornar a administração pública mais flexível, enxuta, eficiente, com serviços de melhor qualidade e custos reduzidos, em contraposição à administração burocrática, caracterizada como onerosa, pesada, ineficiente e prestadora de maus serviços. Para tal, foi proposta a subdivisão do aparelho do Estado em quatro setores: núcleo estratégico; atividades exclusivas; serviços não exclusivos e setor de produção de bens e serviços para o mercado (BRESSER-PEREIRA, 2006).

Partindo dessa subdivisão, cabe uma análise mais focada no setor de serviços não exclusivos, categoria que inclui as universidades públicas.

A reação dos sindicatos, dos docentes, dos técnico-administrativos e dos estudantes, nas universidades públicas, impediu que fosse, formalmente, efetivada a recomendação de transformação dessas instituições em instituições públicas não-estatais. Entretanto, independente do movimento de resistência, identifica-se, na prática, um processo gradual de implementação da política traçada pelo Plano Diretor.

Lima (2007, p. 126) sinaliza que, a partir do Plano Diretor da Reforma do Estado, portanto a partir de 1995, "[...] foi operacionalizada uma crescente desresponsabilização do Estado com a educação superior, por meio da redução de verbas públicas para seu financiamento" propiciando dessa forma" [...] estímulo ao empresariamento deste nível de ensino [...]." Com essa medida, a educação tende a ser inserida no âmbito dos serviços definidos pelo mercado e passa a ser considerada um serviço que pode ser privado ou privatizado.

Sguissardi e Silva Junior (2009) identificam que a referida medida favoreceu a produção de arcabouço jurídico para a reforma das universidades, resultando, assim, no primeiro e decisivo passo para a mercantilização da universidade estatal.

Partindo de uma análise da conjuntura e das medidas legais, tomadas até o momento, pode-se inferir que as políticas de educação superior, 
implementadas a partir dos anos de 1990 apontam para um processo gradual e contínuo de privatização. Esse movimento não se limita à abertura do campo para empreendimentos comerciais de ensino, abrange, também, a privatização interna das instituições de ensino superior públicas que vivenciam uma privatização de forma indireta.

Uma situação comum, que caracteriza esse crescente processo de privatização, são as parcerias constituídas entre as empresas privadas e os institutos de pesquisa das universidades públicas, não raramente, subsidiadas com recursos do Estado.

Nesse contexto, as pesquisas básicas e críticas cedem lugar às pesquisas aplicadas, os professores intelectuais são ofuscados pelos professores empreendedores e as áreas de humanidades e ciências sociais são duramente atingidas, em face do menor apelo comercial dos seus projetos.

Verifica-se, assim, a intensificação da utilização do financiamento privado nas instituições de ensino superior públicas, naturalizando, desse modo, a busca de recursos suplementares para essas instituições, como forma alternativa para a sua manutenção e para a diminuição dos gastos do governo com esse setor.

Constata-se, também, "[...] a naturalização do seqüestro do fundo público pelo capital [...]" (SGUISSARDI; SILVA JUNIOR; SILVA, 2010, p. 12), sobretudo, no financiamento das pesquisas de inovações tecnológicas encomendadas por empresas privadas. Esse fenômeno coloca a inovação como lugar central, conduzindo boa parte da comunidade acadêmica a colaborar de forma consentida, balizando a produção do conhecimento pelos princípios de valorização e reprodução do capital. Os pesquisadores que primam pela análise crítica e se contrapõem a esse modelo de ciência estão, cada vez mais, em menor número, mas são movimentos de resistência, individuais e coletivos, gerados nessa complexa realidade social. Ademais, focos de resistência coexistem com configurações subjetivas que, progressivamente, naturalizam a intensificação do trabalho e a insana busca de tudo quantificar do gerencialismo, de modo a produzir uma "[...] corrida para o sempre mais [...], uma espécie de [...] violenta busca de reconhecimento [...]" que tende a ensejar [...] novas patologias do trabalho [...] e até mesmo "assédio moral" e uma 'moral do assédio' (GAULEJAC, 2007, p. 21 3-229). 
A expansão da educação superior pública e suas implicações no trabalho docente

Fala-se em aumento de produtividade, cumprimento de metas lquase sempre inatingíveis), otimização de recursos humanos e de espaços físicos, enfim, um discurso todo permeado pela lógica empresarial. Defende-se a implantação de um modelo gerencial sem levar em consideração as especificidades de uma instituição pública.

No caso da educação superior pública, a ampliação do seu acesso representa uma das mais importantes políticas de governo direcionada para melhorar os indicadores educacionais do país, bem como contribuir com o seu desenvolvimento. Nessa perspectiva, o Plano Nacional de Educação (PNE), para o decênio 201 1-2020, estabeleceu como meta para esse período elevar a taxa bruta de matrícula na educação superior para 50\% e a taxa líquida para 33\% da população de 18 a 24 anos.

Busca-se implementar nas universidades públicas, sobretudo, nas federais, um plano de reestruturação calcado em uma lógica importada do setor privado, em perfeita sintonia com os princípios da administração gerencialista. É a expansão com precarização, visando, prioritariamente, aumentar o número de vagas. Elevam-se, assim, os indicadores de produtividade do ensino superior público, favorecendo os índices estatísticos do governo, sem resolver, a contento, problemas já existentes, tais como: inadequação de infraestrutura e insuficiência no quadro de docentes e técnico-administrativos.

$\bigcirc$ Reuni, um plano de reestruturação e de expansão das universidades federais - que teve como um dos seus principais objetivos, aumentar o número de vagas de ingresso nos cursos de graduação e otimizar o aproveitamento dos recursos humanos e da infraestrutura física já existentes - retrata bem a incorporação, pelo governo, de uma prática gerencialista do setor privado e o quanto as universidades públicas, em especial, o docente - sujeito do estudo em questão -, estão sendo afetados por essa lógica mercantilista e produtivista, tão característica do mundo do trabalho contemporâneo.

Vale ressaltar que se defende a necessidade urgente de criação de condições de ampliação de acesso e permanência nas universidades, como também a implementação de uma educação superior pública mais inclusiva e democrática. Mas, existem discordâncias de iniciativas, pautadas em uma racionalidade produtivista importada do setor privado, que ampliam, exponencialmente, o número de vagas, favorecendo os indicadores quantitativos do governo em relação ao acesso à educação superior, sem o correspondente 
investimento em infraestrutura, em números de servidores técnicos e docentes e em condições básicas de permanência para os alunos. Somos contrários a medidas que favorecem o esvaziamento do sentido de docência e de universidade e perdem de vista a educação superior pública de qualidade, aprofundando o processo da expansão com precarização, repercutindo nos segmentos dos discentes, técnicos e docentes.

Um projeto societário, distinto do vigente, não se dará simplesmente por ajustes e movimentos expansivos de qualidade duvidosa da educação superior, pela via do atendimento pífio, por exemplo, de jovens antes excluídos desse nível de ensino. Muito menos, por uma expansão universitária que cria distinções entre seus polos e unidades, que privilegia alguns como centros de excelência de pesquisa, deixando outros a uma condição de universidades de ensino, limitados a função de "escolões". Compartilha-se com a inquietação de Sguissardi ao levantar a questão:

Como pensar um país soberano e uma nação plenamente democrática, se os bens públicos universais são vistos como mercadorias ou semimercadorias e a universidade pública é cada vez mais identificada pela ótica empresarial competitiva? (SGUISSARDI, 2005, p. 216$)$

Considera-se pertinente a apresentação no presente tópico de elementos da conjuntura neoliberal que têm servido de sustentação para as atuais mudanças na educação superior pública, mudanças essas que serão apresentadas no item a seguir através de três linhas de estudo.

\section{Considerações sobre as pesquisas do grupo trabalho docente na expansão da educação superior}

No ano de 2013, o coletivo de pesquisadores deu prosseguimento à atualização do banco de dados ${ }^{4}$ sobre a produção do conhecimento acerca da categoria trabalho docente na educação superior. A pesquisa empírica, por sua vez, contempla os seguintes eixos de análise:

- Trabalho Docente na Expansão da Educação a Distância (EAD).

- Trabalho Docente na Expansão da Pós-Graduação.

- Trabalho Docente na Expansão da Graduação. 
A expansão da educação superior pública e suas implicações no trabalho docente

Para operacionalização dessa pesquisa, o grupo dividiu-se conforme tais eixos e conta com o apoio financeiro dos seguintes órgãos de fomento: Fundação de Amparo à Pesquisa do Estado de São Paulo (FAPESP); Observatório da Educação (OBEDUC/CAPES) e do Conselho Nacional de Desenvolvimento Científico e Tecnológico (CNPq).

Oeixo trabalho docente na expansão da Educação a Distância reúne professores de várias universidades (Universidade do Estado do Rio de Janeiro/ UERJ, Universidade Federal Fluminense/UFF, Universidade Federal Viçosa/UFV e Universidade Veiga de Almeida/UVA) que realizam um estudo de caso sobre a Fundação Centro de Educação a Distância do Estado do Rio de Janeiro (CEDERJ).

Cederi é um consórcio formado por sete instituições de educação superior públicas do Estado do Rio de Janeiro. Destaca-se, nas análises preliminares, o papel central das tecnologias da informação e do ensino a distância (EAD) na agenda da expansão da educação superior no Brasil, tal como apontado na evolução de suas matrículas.

Evolução das matrículas à distância no ensino superior brasileiro (1995-2012)

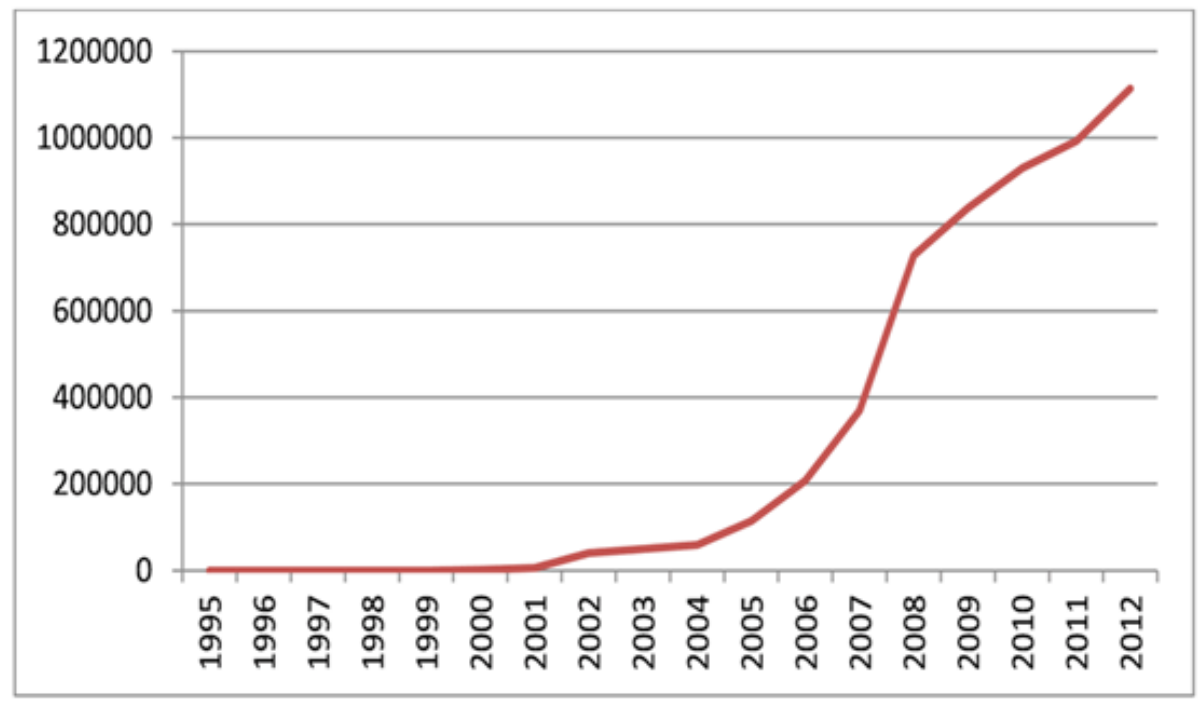

Fonte | BRASIL/MEC/Inep. Sinopses estatísticas do Censo da Educação Superior 1995 a 2012. 
Esse consórcio conta, hoje, com mais de 30 mil alunos em cursos de graduação. No último vestibular em 2014 , foram ofertadas 6.589 vagas em 14 cursos, distribuídos em 34 polos. Os cursos predominantes são os de formação de professores, mas também há cursos ligados a áreas estratégicas direcionadas para as demandas do governo do estado do Rio de Janeiro, especialmente no contexto dos grandes eventos (ex: Turismo e Segurança Pública). Em relação à terminalidade dos cursos, aponta-se que, do total de alunos das turmas concludentes, entre 2005 e 2012 , somente 17,2\% dos estudantes concluíram seus cursos.

Quanto ao quadro efetivo de servidores, o único concurso público do Cederi ocorreu em 2013 (anteriormente, aconteciam apenas seleções para contratos temporários). Todavia, o concurso em questão abriu vagas, apenas, para cargos operacionais, como webdesign, e isto não significou a estabilidade de conteudistas e coordenadores de disciplina e, ainda menos, dos tutores. Estes não foram contemplados por concurso, continuando a receber e trabalhar no sistema de bolsas de estudo. Eis a forma precarizada de trabalho expressa nessa modalidade específica de ensino.

A pesquisa, em fase de conclusão, conta com uma análise de um questionário respondido por uma amostra de 59 profissionais, envolvendo tutores, conteudistas, coordenadores e webdesigns laproximadamente 15\% do total das categorias que atuam no Cederj - 409 pessoas). Quanto aos tutores, se constatou que: 57,14\% têm mestrado completo; 32, 14\% têm o doutorado completo; $77,27 \%$ dos tutores consideram a tutoria como um tipo de trabalho docente; 50\% a consideram como trabalho de apoio pedagógico e 22,73\% como trabalho de natureza técnica. A maior parte dos tutores atua em EAD há mais de 5 anos. Muitos tutores $(64,29 \%)$ já exerceram ou exercem, atualmente, outras funções no EAD (conteudistas, coordenadores). Em termos salariais, $81,48 \%$ dos tutores recebem entre $R \$ 600,00$ e $R \$ 1.200,00$, e somente $7,40 \%$ indicam ter remuneração acima de $R \$ 1.800,00$.

Entrevistas estão sendo realizadas e poderão fornecer elementos de interpretação dos dados previamente coletados, mas já evidenciam o grande volume de trabalho e as precárias condições de contrato e salário (MANCEBO; VALE; MORAIS; ÁVILA; MEIRELES; MATTOS, 2014).

Compreende-se que uma lógica tecnificada e instrumental, por vezes evidenciada de forma clara na EAD, ou mesmo na educação profissional e 
A expansão da educação superior pública e suas implicações no trabalho docente

tecnológica, está intimamente também relacionada a uma modalidade da educação superior cuja vinculação com os processos econômicos e políticos assinalados na introdução são incontestes: a da pós-graduação. Esta, polo irradiador da Reforma do Estado e de seus princípios para toda a área da Educação brasileira, se apoia em dois sustentáculos: no desenvolvimento da Ciência, Tecnologia e Inovação; e na Internacionalização.

eixo trabalho docente na expansão da pós-graduação representado pelo grupo "Economia Política da Educação e Formação Humana" da Universidade Federal de São Carlos (UFSCar) desenvolveu a pesquisa intitulada: "O trabalho do professor diante da pós-graduação em educação: o caso da região sudeste", com relatório final já consolidado (SILVA JÚNIOR, 2014). Foi efetivado um estudo de caso sobre a pós-graduação da Universidade Federal de Minas Gerais (UFMG), com foco mais central para o programa de pós-graduação em educação dessa instituição, na compreensão das consequências da mundialização da educação superior no trabalho do professor.

A racionalidade econômica permeia a institucionalidade da UFMG com estruturais consequências para a política de pós-graduação e pesquisa e para a natureza do trabalho da UFMG e outras instituições federais de ensino superior mineiras. O Plano Mineiro de Desenvolvimento Integrado (PMDI) propõe fomentar a inovação tecnológica em Minas Gerais, definindo para o governo do estado o papel de articular o setor produtivo, universidades e centros de pesquisas.

A Universidade Federal de Minas Gerais (UFMG) "expandida" inclui um conjunto de ações de parceria e colaboração com instituições internacionais que contribuem para a consolidação de sua inserção no cenário acadêmico nacional e internacional. Verificou-se que, no programa de pós-graduação em educação (PPGE) da UFMG, 39\% do corpo docente recebe bolsa de produtividade. A avaliação do último triênio (2010-2012), publicada em dezembro de 2013 , aponta que, apenas, três Programas de pós-graduação em educação atingiram nota máxima, dentre eles, um na UFMG (os outros dois estão na UERJ e na UNISINOSI.

$\bigcirc$ programa da UFMG investe em convênios interinstitucionais e diversas pesquisas conjuntas com universidades estrangeiras. Em 2009, o PPGE/UFMG foi o pioneiro na implantação do Doutorado Latino- Americano em Educação. Os professores do PPGE/UFMG, no ultimo triênio avaliado, 
destacaram-se, nas coordenações de Programas junto ao Ministério da Educação (MEC) e em comissões nacionais de avaliação, diretorias de associações científicas nacionais e internacionais. O PPGE/UFMG apresenta crescente ascensão na internacionalização e forte organização administrativa e pedagógica. Tal crescimento, no entanto, requer, por parte dos professores que permanecem na instituição, uma política de assunção "voluntária" diante de demandas que ficam descobertas nas suas unidades acadêmicas, resultando em concentração de tarefas e intensificação de trabalho. Ademais, esse contexto produz relações de trabalho interesseiras e uma competitividade desenfreada, de modo a gerar a naturalização desse quadro por alguns docentes, e desilusões de outros em torno da constituição da universidade, enquanto instituição crítica e socialmente comprometida com um ideal de transformação social, como se aponta na parte final deste artigo.

Obviamente, se trata de um desenvolvimento institucional que se diferencia, sobremaneira, das demais IFES, sobretudo, dos campi interiorizados nos grotões do Brasil. É inconteste que se trata de desenvolvimentos desiguais com condições, de realização de trabalho acadêmico, bem diferenciadas.

Enfim, o terceiro e último eixo reúne pesquisadores de diferentes instituições: Universidade Federal do Maranhão (UFMA), Universidade Federal de São Carlos (UFSCar) e Universidade Federal Fluminense (UFF).

Os pesquisadores da UFMA que analisaram as repercussões do Reuni, no trabalho docente e na cultura das IFES, apontam para as contradições e desigualdades da expansão. Este grupo tomou como campo empírico as seguintes instituições: Universidade Federal do Maranhão/UFMA, Universidade de Brasília/UnB e Universidade Federal do Tocantins/UFT. A escolha dessas instituições ocorreu na direta dependência do que foi analisado nos dois primeiros anos da investigação, especialmente, dos dados extraídos do Relatório de Acompanhamento do Reuni de 2010 da Associação Nacional de Dirigentes das Instituições Federais de Ensino Superior (ANDIFES, 2010). Essa seleção é orientada pelo percentual de aumento do número de vagas nos cursos de graduação presencial, no período 2006/2010, sendo escolhidas as seguintes universidades com significativo aumento de oferta de vagas discentes: região Norte (Universidade Federal do Tocantins (UFT) - 76\%), região Centro-Oeste (Universidade de Brasília (UnB) - 86\%) e região Nordeste (Universidade Federal do Maranhão (UFMA) - 54\%). 
A expansão da educação superior pública e suas implicações no trabalho docente

São explícitos os dados referentes às distinções entre matriz e interior, entre instituições ou campi com trajetória longa ou mais recente, assim como as questões referentes às decisões de recursos do Reuni, investidos em distintas áreas e unidades que, no contexto da precarização generalizada, são bem ou mal contempladas, mas, invariavelmente, sob o eixo da escassez.

Os documentos apontam que a reestruturação e a expansão na UnB já eram algo pensado mesmo antes do Reuni, e quando este foi lançado complementou a proposta que a instituição tinha de expandir e tornar a universidade mais acessível. Desta forma, novos campi foram criados e diversas estratégias foram estabelecidas para que as metas apontadas pelo Programa fossem cumpridas. Seis anos após a adesão da UnB ao Reuni, o que se observa é uma expansão física e um aumento de vagas muito grande. A falta de uma melhor avaliação e de uma discussão mais aberta para debater as metas que foram estipuladas parece ser uma das principais falhas do Plano de Reestruturação e de Expansão das Universidades Federais (Reuni), e, atualmente, as consequências disso são visíveis. Obras inacabadas, precária assistência estudantil, superlotação em algumas salas de aula, enquanto em outras há uma grande evasão, são alguns dos problemas constatados na UnB (LEDA; COSTA; 160 CORDEIRO, 2014).

No caso da UFT, entender o significado do Reuni, requer a compreensão de peculiaridades anteriores que ajudam a explicar os motivos pelos quais levaram essa IFES a vivenciar a situação em que se encontra atualmente. A UFT viveu um processo de transição entre a herança institucional oriunda da Universidade do Tocantins (UNITINS) e a adaptação da universidade nos moldes requeridos pelo capital. Tal processo vem exigindo muito trabalho por parte de quem constrói o cotidiano da instituição, especialmente docentes e técnicos. Mesmo diante de suas dificuldades, o Reuni, na UFT, diversificou os cursos e possibilitou a ampliação de oportunidades e desenvolvimento ao povo dessa região. A questão da infraestrutura foi considerada pelos entrevistados como um fator comprometedor do Reuni e também um dos principais responsáveis pela precarização e intensificação do trabalho docente. Um corpo docente em número restrito diante da enorme demanda de trabalho; excesso de carga horária dos professores e escassez de recursos, delineiam um cenário acadêmico restrito ao ensino, com atividades de extensão e de pesquisa praticamente inexequíveis. $O$ caso da UFT, que vivenciou a transição do velho modelo para a modernização da instituição nos moldes do capital, carrega especificidades 
que demandam análises bastante cuidadosas (COSTA; BRAGA; FERREIRA, 2014).

No caso da UFMA, embora essa instituição tenha criado parte dos seus campi antes dos anos 80 , a sua expansão efetiva é um fenômeno mais recente, que ocorreu, principalmente, após o ano de 2007, quando o MEC propôs o Reuni. Durante esse Programa, ocorreu um expressivo crescimento da instituição, não somente em relação ao número de vagas da graduação, mas também no que diz respeito à pós-graduação. Isso gerou um descompasso entre o número de alunos matriculados e o quantitativo de trabalhadores efetivos (docentes e técnicos) na instituição. Entre 2007 e 2013 , houve um aumento de $63,8 \%$ no número de discentes na graduação, enquanto o aumento do número de docentes efetivos foi de somente 43,3\%. $\bigcirc$ número insuficiente de servidores técnico-administrativos, trabalhando na assessoria das atividades acadêmicas, sobrecarrega ainda mais o já diminuto quadro de professores da UFMA, abrindo espaço para a precarização e intensificação do trabalho docente. É a expansão com precarização, visando, prioritariamente, elevar o número de vagas ofertadas e os indicadores de produtividade do ensino superior público, deixando de resolver, a contento, problemas históricos existentes (RIBEIRO; DANTAS; SILVA, 2014).

Ainda nesse mesmo eixo de análise, a pesquisa "Trabalho, subjetividade e saúde do professor no contexto de expansão da universidade pública: estranhamento, sofrimento e prazer", desenvolvida por um dos pesquisadores do grupo, tomou, como campo empírico, a UFF. A esta se soma as pesquisas de dois outros pesquisadores do grupo, que resultaram nas dissertações "Política de pessoal docente do governo Lula: uma análise do Reuni na UFF e seus desdobramentos" (GREGÓRIO, 201 1) e "O REUNI como estratégia da contrarreforma da educação" (RODRIGUES, 2011 ). A UFF foi escolhida por ser uma das duas maiores universidades federais do estado do Rio de Janeiro la outra é a Universidade Federal do Rio de Janeiro/UFRJ, isso tanto em número de alunos, quanto em número de professores e técnicos), e por possuir um perfil voltado para ensino de graduação e interiorização. Ademais, o Relatório de Acompanhamento do Reuni da Andifes, de 2010, demonstrou que a UFF expandiu suas vagas discentes na graduação em $63 \%$.

A Fase de Expansão I na UFF (2003 a 2007) e nas demais universidades visou interiorizar a educação superior pública federal. A Fase de Expansão 
II (2007 a 20 12) teve como mote os objetivos do Reuni, explicitados, anteriormente, neste texto, e a implantação desse Programa.

As pesquisas sobre a UFF demonstram que houve um agressivo crescimento do número de alunos, com falso incremento da força de trabalho quando se consideram as aposentadorias (GREGÓRIO, 201 1), e distribuição de vagas distintas entre os polos da UFF, com vantagens para o de Volta Redonda, "vitrine" do Reuni na UFF, e desvantagens para polos como Nova Friburgo (RODRIGUES, 2011 ) e Rio das Ostras (SILVA, 2013). A precarização e a intensificação do trabalho nos polos interiorizados geram forte desmotivação e frustração nos docentes, sendo que os aspectos de sua subjetividade e saúde serão mais bem pormenorizados no item seguinte.

No que diz respeito a essa expansão no conjunto das universidades federais, a análise do relatório da comissão constituída pela Portaria $n^{\circ}$ 126, de 19 de julho de 2012 (BRASIL; MEC; SESU, 2012), incumbida de acompanhar as ações do MEC, evidencia que há a perspectiva de que a expansão seja concebida como processo contínuo e cumulativo até que sejam atingidas as metas previstas para o ensino superior pelo Plano Nacional de Educação (201 1-2020). Os números da expansão das IFES (2007/2012) 162 apontam para aumento de 71,5\% de vagas na graduação 1139.875 em 2007, para 239.942 em 20121, contraposto ao de 47,5\% do número de docentes (45.849 em 2007, para 67.636 em 2012 ) e 10,7\% de técnico-administrativos (88.801 em 2007, para 98.364 em 2012), o que corrobora a tese da intensificação do trabalho (SGUISSARDI; SILVA JÚNIOR, 2009) identificada nos estudos supracitados sobre o Reuni na UFMA, UnB, UFT e UFF.

A infraestrutura precária é referida em muitas falas dos entrevistados e em questionários das diversas pesquisas realizadas: "Segunda turma se formando sem laboratório" (DOCENTE UFMA 1, 2013); "Universidade de lata5" (DOCENTE UFF 1, 2013 ); "Nós tivemos que passar seis meses", lamentou um entrevistado "[...] andando nesse sol, nessa temperatura agradável", ironizou, "[...] pra ter acesso a um banheiro, a um bebedouro", ou ainda, "[...] pra poder usar o bloco de sala de aulas". Ao que completou: "[... já não tinha onde ter aulas, porque o curso foi andando" (DOCENTE UFT 3, 2013). Outro docente sinalizou que houve uma "expansão física" (ex: prédios), que implicou em disputas e decisões um tanto complicadas: "[... ] não dá para todos os cursos, para todos os departamentos [... ]", alegou, o que implicaria, então, em se 
decidir "[...] quem vai ou quem não vai $[\ldots]$ ", o que é, na visão do professor, "[...] uma coisa dificílima de resolver" (DOCENTE UNB 1, 2013).

Nas pesquisas sobre o Reuni identificou-se um cotidiano laboral intensificado e regido pela lógica gerencialista, constituído por uma gama de obrigações que sobrecarrega o professor, e por um ambiente organizacional que tende a valorizar o profissional multifacetado. Frequentemente, os docentes se ressentem diante do tempo exíguo para uma maior dedicação às suas atividades-fim e pela falta de familiaridade/afinidade com algumas tarefas extras que thes são impostas.

\section{Trabalho e subjetividade do professor: da captura ao adoecimento}

Tempo de vida do trabalhador docente tende a ser capturado pelo tempo de trabalho, o que se reforça, nas condições materiais e objetivas do trabalho do professor universitário, algo que tem intrínseca relação com a atividade profissional dessa categoria. Conforme argumenta Borsoi (2012, p. 831, o trabalho docente, "[...] por sua natureza [...] permite que o professor o realize também $[\ldots]$ fora do ambiente institucional $[\ldots], e$, assim, $[\ldots]$ extrapole amiúde os limites específicos da jornada regimental contratada [...], pois, como aponta, [...] um computador conectado à internet e um telefone são suficientes para que mantenham seu elo com a instituição, onde quer que estejam." Forja-se, assim, o quê Gauleljac e Aubert (1 991 1) denominam "attachment", isto é, vínculo ao qual se liga, e do qual não se consegue despreender. Algumas falas são emblemáticas:

Eu, praticamente, já têm uns três finais de semana que eu não tenho final de semana em casa, eu trabalho lá, mas não estou lá. [...] Eu preciso ter tempo, eu acabo utilizando o espaço da família pra fazer o trabalho que a gente não consegue fazer tudo aqui (DOCENTE UFT 3, 2013, grifo nosso).

$[\ldots]$

A gente fica tão emprenhado nesse fazer pesquisa, nesse fazer docência, fazer ciência, que eu não consigo fazer essa distinção tão nítida onde que começa a vida privada e onde que começa a vida acadêmica. Porque muitas vezes as coisas vão pra dentro da casa da gente (DOCENTE UFMA 6, 2013). 
A expansão da educação superior pública e suas implicações no trabalho docente

tempo de férias, também, parece se confundir com o tempo de produção, o relato de um professor sinaliza, claramente, esse embaralhamento dos tempos e espaços de vida profissional e pessoal:

Em 10 anos de universidade, eu nunca saí de férias, nunca. Minha esposa está pressionando pra eu sair de agora, eu tenho 30 dias, mas mesmo saindo por 30, eu tenho 3 finais de semana em Pernambuco dando aula, é minha característica, talvez a minha personalidade, num sei, talvez um psicólogo explique (DOCENTE UFMA 4, 20131.

Embora assumamos que inexiste trabalho sem envolver desprazer ou sofrimento, ou, seguindo Dejours (2004), que prazer-sofrimento são indissociáveis, faz-se mister apontar que a questão do prazer no trabalho docente só é passível de ser objetivada em uma dada condição concreta: a de precarização e intensificação, em que pese as contradições e diferenças desses contextos, conforme instituição em análise.

A entrevista de uma professora permeada por vivências concomitantes de prazer e sofrimento em face das adversidades da expansão e interiorização 164 da UFT, corrobora essa afirmação de Dejours (2004).

Eu cheguei aqui em Araguaína, foi um choque! Primeiro que a região era nova, nova no sentido de ser basicamente nada, nem prédio nós tínhamos aqui. Então foi um envolvimento muito grande com o trabalho de construção da universidade e aí a gente foi tomando gosto e ficando aqui e pegando aqui esse jeito que eu chamo de jeito nortista de trabalhar. Você vai fazendo as coisas e vendo acontecer, dá muito trabalho, mas também dá muito prazer (DOCENTE UFT 2, 2013).

Apesar de os docentes estarem imersos em um contexto tão adverso, a maioria tende ainda a considerar o espaço acadêmico, sobretudo a sala de aula, como um lugar de autonomia, e até mesmo de criação e realização profissional. Não obstante, tal realidade, identificou-se, em alguns entrevistados a necessidade de forjar a ideia de que subexiste a universidade que possa se conformar aos seus objetivos. Comparecem, em algumas falas dos professores, certas posturas defensivas mediante as quais tendem a minorar os riscos a que estão expostos. $\bigcirc$ relato que segue expressa bem essa tendência: 
Acho que quando você faz com paixão, o que você ama, você consegue [...] aí não tem REUNI, não tem salário, eu acho que a gente trabalha muito, se você for levar em consideração o não, o não, as coisas negativas, você não iria trabalhar mesmo [...] (DOCENTE UFMA 6, 2013).

[...]

Uma coisa que me chateia na Universidade, algumas situações de pessoas que não têm é... paixão pela Universidade, pela docência e que muitas vezes querem, estão aqui mais para utilizar a Universidade para seu próprio benefício e não pelo benefício da sociedade que é o que nós temos que fazer. Então isso me chateia e ai você vê as vezes que isso compromete a qualidade do trabatho (DOCENTE UNB 6, 2013).

Vale destacar que, em questionário respondido por mais da metade de professores de um polo do interior da UFF, notadamente marcado pela precarização e intensificação do trabalho, obteve-se a resposta unânime de que são, no mínimo, adversas as condições de pesquisa ladjetivadas como inexistentes, péssimas ou insuficientes). Entretanto, uma das entrevistadas, jovem e produtiva, que admitiu frustração com as parcas possibilidades de infraestrutura para pesquisas no polo, dizia acreditar em melhorias. Relatou que fazia pesquisa mesmo não havendo condições ideais, e que não se tratava de "pesquisa de ponta", como desejava e tinha qualificação para, mas que era "relevante." Seu discurso parecia indicar uma necessidade de autoconvencimento. Relatou que considerava necessário "ter que acreditar" em boas perspectivas para sua carreira estando vinculada ao polo interiorizado. Sua postura defensiva tinha uma função adaptativa, já que procurava evitar a aparição do sofrimento ou de emoções que poderiam lhe ser desestabilizadoras (SILVA, 2013).

Há uma dimensão ética e política do sofrimento e/ou adoecimento docente, intrinsecamente relacionada à condição institucional da universidade em pauta, das características de sua expansão, que, por outro lado, não é um fato isolado, mas imbricado ao contexto macro, econômico e político, referenciado no item introdutório deste artigo. Subjetividades forjadas na sociabilidade produtiva, ainda que possam ser refratárias aos seus ditames desumanizantes, também são refratadas de seus ideais éticos e políticos, devido à condição objetiva, limitada, de sua atividade laborativa. Nesta, tais ideais tendem a ser reificados, tamanha a frustração em face de uma universidade que se afasta do que um professor da UFF nomeou como sua "função social". $\bigcirc$ que, não 
A expansão da educação superior pública e suas implicações no trabalho docente

obstante, como alentou outro docente, por vezes, contraditoriamente, fomenta a universidade como lócus ou instituição de formação "não só técnica", mas também de conscientização e "formação política" (SILVA, 2013).

Apesar da existência de defesas frente aos fatores patogênicos de trabalho que atenuam os riscos de adoecimento, o não reconhecimento de fragilidades e de sofrimentos, em contextos onde sobrevive o "mais forte", pode, como consideram vários professores, torná-los mais vulneráveis. $\bigcirc$ adoecimento é maior do que se imagina, sendo, por vezes, sorrateiro, ofuscado, negado, encoberto, além de estigmatizado e, consequentemente, subnotificado. Dados sobre afastamento de docentes por problemas de saúde coletados na UFF (SILVA, 2013) indicam que, dos 208 docentes afastados, em 2012, 72 foram por transtornos mentais e de comportamento (predomínio de problemas de depressão, fobia, ansiedade e estresse). A prevalência de transtornos mentais e comportamentais e de doenças osteomusculares em professores também foi identificada em recente estudo epidemiológico descritivo relativo a adoecimento de docentes da UnB (SOUSA, 2013).

Assim, a doença ou problemas de saúde mental, em si mesmos não visíveis, se desenvolvem ou tendem a se desenvolver como doença insidiosa, 166 podendo ser utilizada a metáfora da droga e do câncer para analisar o adoecimento do professor capturado pela sociabilidade produtiva e, acrescente-se, impedido, em muitos momentos, de concretizar em seu cotidiano, seus almejados anseios e intencionalidades, éticos e políticos, de transformação social; ou, no mínimo, de realização de sua "missão", de "ser professor", de "ser pesquisador". Pesquisando a dor dos professores, notam-se frágeis formas de reconhecimento, mais pautadas em números e metas do que no real do trabatho, minimizando, desta forma, as chances da transformação do sofrimento em prazer pela mediação do trabalho, como aponta Dejours (2004).

De qualquer forma, considera-se necessário jogar luz no caso do professor que quase não vive mais sem o trabalho (intensificado), sem constituir-se com este uma relação que remete ao conceito de "attachement" (GAULEJAC; AUBERT, 19911. Aí a metáfora da droga, substância da qual não consegue se livrar, e, ao mesmo tempo, gera prazer, mas causa infortúnios, dependência, e, ademais, o sentimento de que, sem ela (o "trabalho-droga"), não mais se sobreviveria. Uma sobreimplicação do prazer no trabalho, que, conforme aponta Mancebo (2007), recai em sentimentos de urgência, estresse e sensação, explicitados por alguns entrevistados da UFF, em expressões como: "[...] 
faz, faz, faz [...], mas [...] não se dá conta, não se dá conta, não se dá conta $[\ldots]^{\prime \prime}$, num cotidiano [...] saco sem fundo [...], no qual se trabalha mais do que se devia, e, mesmo assim, fica-se sempre "a dever" (SILVA, 2013, p. 101-102).

Muitas falas emblemáticas foram ditas, tal como a do professor que "não explode, mas implode", e outras tantas foram registradas, ecoando, em outras pesquisas, na UFT e UnB:

Tô fazendo acompanhamento com psiquiatra. Ele disse que eu estou profundamente triste. Mas assim, na verdade, é excesso de trabalho (DOCENTE UFT 3, 2013).

$[\ldots]$

Eu engordei 7 quilos na gestão. [...] Eu não tinha hipertensão, antes de vir trabalhar na universidade. Não tinha os quilos que eu tenho hoje. Tudo isso. Enfim, corria, fazia um exercício físico, sempre. Eu tinha alimentação mais regrada. Mas eu tô aqui, acabo comendo qualquer porcaria por aqui, porque fica em reunião direto. Interfere muito. Principalmente quem assume cargo de gestão, é o que mais se desgasta com saúde (DOCENTE UNB 5, 2013).

Uma resposta de um professor de campi interiorizado, inconformado com a precariedade de seu polo, é exemplar no sentido de evidenciar a produção institucional do adoecer, as desigualdades dos desenvolvimentos institucionais, assim como as estratégias de defesa que podem ser bem ou malsucedido:

Eu vivo pensando em me transferir ou fazer concurso pra outro lugar, mas fico achando que eu não conseguiria, porque eu publiquei pouco, e publiquei tão pouco porque fiquei sobrecarregado, estressado, doente, e depois deprimido. $O$ que fez com que eu 'ressuscitasse' um pouco foi que eu comecei a escrever denúncias e textos "militantes", e daí me aproximei muito de outras pessoas que também estavam muito incomodadas com a situação do polo e tentando mudá-las... E agora eu fico com medo de me transferir pra um outro lugar, ele ter problemas estruturais parecido com os daqui, e eu ainda por cima não conseguir me entrosar lá. De vez em quando eu penso em abandonar a vida acadêmica e ir pra outro país (DOCENTE UFF 2, 2013).

Assim, a saúde do professor e sua subjetividade são colocadas numa encruzilhada com a sociabilidade produtiva, de forma a produzir parcas 
A expansão da educação superior pública e suas implicações no trabalho docente

possibilidades sublimatórias e de reconhecimento, resultando no predomínio de estratégias de mediação defensivas em face das adversidades da sua rotina de trabalho e em casos numericamente pouco expressivos de adoecimento, mas qualitativamente muito preocupantes.

\section{Considerações finais}

$\bigcirc$ presente estudo teve o objetivo de analisar a expansão da educação superior pública e suas implicações no trabalho docente. Procurou investigar como os professores de distintas instituições de ensino estão se mobilizando para lidar com as repercussões da expansão e reestruturação da educação superior pública, buscando alternativas para enfrentar uma rotina marcada por precarização e intensificação no seu cotidiano laboral.

Considera-se que o processo de reconfiguração da educação superior pública - seja na modalidade presencial, tanto na graduação ou na pós-graduação, ou na EAD - tem afetado diretamente a categoria dos trabalhadores docentes, tornando-os tanto manipuláveis como vulneráveis ao estresse e ao

168 adoecimento.

Tal movimento não está finalizado, conforme aponta o relatório da comissão incumbida de acompanhar as ações do MEC, de que a expansão seja concebida como processo contínuo e cumulativo até que sejam atingidas as metas previstas para o ensino superior pelo Plano Nacional de Educação (201 1-2020). Cabe apontar que os IF's (Institutos Federais de Tecnologia) também entraram, nesse processo, de expansão desenfreada, mas esse campo ainda será mais bem investigado, posteriormente, pelo grupo de pesquisa intitulado "Trabalho Docente na Expansão da Educação Superior."

A partir das análises dos resultados dos estudos realizados pelo grupo de pesquisadores, constatou-se que há mais semelhanças do que diferenças entre as vivências dos docentes entrevistados das distintas instituições de educação superior pública, mesmo considerando, as diferentes realidades e desiguais condições de trabalho, por vezes, reunidas em uma única instituição, sobretudo, quando são feitas comparações entre o campus sede e os campi da interiorização.

Há uma crescente precarização e intensificação do trabalho docente, fruto de um contexto mais amplo determinado por políticas da educação 
superior em nível do governo federal, que impõe regras comuns e, especialmente, algumas amarras, delineando, dessa forma, uma cultura acadêmica marcada por princípios do modelo gerencialista. As instituições pesquisadas, como um todo, revelam um cotidiano atravessado por uma racionalidade instrumental e pragmática importada do setor privado.

Nesse contexto, identifica-se, na análise dos processos intersubjetivos utilizados pelo docente, o predomínio do uso de estratégias defensivas, que funcionam como uma alternativa paliativa frente ao sofrimento e limitam-se a negar ou minimizar a percepção de situações desprazerosas, "[...] a operação é estritamente mental, já que ela geralmente não modifica a realidade de pressão patogênica" (DEJOURS; ABDOUCHELI, 1994, p. 128). As estratégias surgem, dessa forma, como recurso de adaptação aos constrangimentos, impostos pela lógica do modelo gerencialista.

Entende-se que é de extrema importância que o docente se identifique com sua atividade profissional e goste do seu trabalho. Mas, é necessário avaliar o quanto essa relação dita "prazeroza" está encobrindo dissabores. Estas são algumas das questões que precisam ser investigadas com mais profundidade: $\bigcirc$ trabalhador docente está lançando mão de estratégias defensivas para mascarar o seu sofrimento? A paixão pela docência é utilizada para justificar e naturalizar a dedicação exacerbada ao trabalho? $\bigcirc$ docente capturado pela ideologia da excelência, não está restringindo o seu tempo de vida ao trabalho, em detrimento da dedicação de tempo necessário a outras esferas?

A paixão pela docência não pode funcionar como estratégia defensiva de resignação favorecendo uma postura acrítica em face das condições adversas de trabalho. A dedicação profissional não deve ser confundida com uma atitude passiva que naturaliza a lógica gerencialista e cultua princípios de individualismo e competitividade, minimizando os problemas do contexto laboral.

Há de se considerar que as inovações nos modos de cooptação da classe trabalhadora encontram resistências de sujeitos que, com análises críticas, percebem o que está por trás das diversas estratégias de cooptação e têm, na contramão dos acontecimentos, mantido posturas (individuais ou coletivas) de denúncia e combate das políticas educacionais em curso, que perdem de vista a educação superior pública de qualidade, aprofundando o processo 
da expansão com precarização, repercutindo nos segmentos dos discentes, técnicos e docentes.

\section{Notas}

1 Abstract feito por Fernanda Massi.

2 Resumen feito por Fernanda Massi.

3 A temática do trabalho docente na expansão da educação superior configura um subprojeto integrante de um projeto maior - constituído por sete subprojetos - intitulado "Políticas da Expansão da Educação Superior no Brasil", que ocorre no âmbito da Rede Universitas/Br e é financiado pelo Observatório da Educação (OBEDUC/CAPES).

4 Um dos produtos da etapa 2009-2013 foi a consolidação de um banco de dados, que pode ser consultado no endereço http://www.anped 11 . veri.br.

5 Referência às aulas ministradas em containers.

\section{Referências}

170 ANDIFES. Associação Nacional dos Dirigentes das Instituições Federais de Ensino Superior. Relatório de acompanhamento do Programa de Apoio a Planos de Reestruturação e Expansão das Universidades Federais (REUNI): o Brasil e sua gente estão nas Universidades Federais. Brasília: ANDIFES, jan. 2010.

BORSOI, Izabel Cristina Ferreira. Trabalho e produtivismo: saúde e modo de vida de docentes de instituições públicas de Ensino Superior. Cadernos de Psicologia Social do Trabalho, São Paulo, v. 15, n. 1, p. 81-100, 2012.

BRASIL. MEC. INEP. Sinopses estatísticas do censo da educação superior: 1995 a 2012. Brasilia: MEC, 2013. Disponível em: http://www.inep.gov.br/superior/censosuperior/ sinopse/default.asp. Acesso em: 10 fev. 2014.

SESU. Portaria $\mathbf{n}^{\circ} \mathbf{1 2 6}$, de 19 de julho de 2012. Institui comissão incumbida de acompanhar as ações do Ministério da Educação com vistas à consolidação do processo de expansão das universidades federais e de tratar dos assuntos estudantis correlatos ao tema. Análise sobre a expansão das universidades federais 2003 a 2012. Brasília: MEC, 2012.

Análise sobre a expansão das universidades federais 2003 a 2012. Brasília: MEC, 2012. 
BRESSER-PEREIRA, Luiz Carlos. Da administração pública burocrática à gerencial. In: BRESSER-PEREIRA, Luiz Carlos; SPINK, Peter (Org.). Reforma do Estado e administração pública gerencial. 7. ed. Rio de Janeiro: Editora Fundação Getúlio Vargas, 2006.

CHANLAT, Jean-François. Ciências sociais e management: reconciliando o econômico e o social. São Paulo: Atlas, 1999.

gerencialismo e a ética do bem comum: a questão da motivação para o trabalho nos serviços públicos. In: CONGRESO INTERNACIONAL DEL CLAD SOBRE LA REFORMA DEL ESTADO Y DE LA ADMINISTRACIÓN PÚBLICA, 7; 2002, Lisboa. Anais... Lisboa: CLAD, 2002.

CHESNAIS, François. A mundialização do capital. São Paulo: Xamã, 1996.

COSTA, Evelyn Hellen Sousa Costa; BRAGA, Lucelma Silva; FERREIRA, Ruan Marcus de Jesus Pinheiro. $\bigcirc$ processo de expansão das universidades brasileiras e os impactos no trabalho docente: elementos para análise da Universidade Federal do Tocantins. In: SEMINÁRIO NACIONAL UNIVERSITAS/Br, 22; 2014, Natal. Anais... Natal: Universidade Federal do Rio Grande do Norte, 2014. 1 CD-ROM.

DEJOURS, Christophe. Sofrimento e prazer no trabalho: a abordagem pela psicopatologia do trabalho. In: LANCMAN, Selma; SZNELWAR, Laerte (Org.). Christophe Dejours: da psicopatologia à psicodinâmica do trabalho. Rio de Janeiro: Fiocruz, 2004.

DEJOURS, Christophe; ABDOUCHELI, Elisabeth. Itinerário teórico em psicopatologia do trabalho. In: DEJOURS, Christophe; ABDOUCHELl, Elizabeth; JAYET, Christian. Psicodinâmica do trabalho: contribuições da escola dejouriana à análise da relação prazer, sofrimento e trabalho. São Paulo: Atlas, 1994.

DOCENTE UFF 1. Entrevista. Rio das Ostras, (RJ), 5 fev. 2013.

DOCENTE UFF 2. Entrevista. Rio das Ostras, (RJ), 6 fev. 2013.

DOCENTE UFMA 1. Entrevista. São Luís, (MA), 11 mar. 2013.

DOCENTE UFMA 4. Entrevista. São Luís, (MA), 20 mar. 2013.

DOCENTE UFMA 6. Entrevista. São Luís, (MA), 23 mar. 2013.

DOCENTE UFT 2. Entrevista. Palmas, (TO), 2 abr. 2013.

DOCENTE UFT 3. Entrevista. Palmas, (TO), 4 abr. 2013.

DOCENTE UNB 1. Entrevista. Brasília, (DF), 20 ago. 2013. 
A expansão da educação superior pública e suas implicações no trabalho docente

DOCENTE UNB 5. Entrevista. Brasília, (DF), 27 ago. 2013.

DOCENTE UNB 6. Entrevista. Brasília, (DF), 26 nov. 2013.

GAULEJAC, Vicent. Entrevista: ideologia, poder gerencialista e fragmentação social. Aparecida (SP): Ideias \& Letras, 2007.

GAULEJAC, Vicent de; AUBERT, Nicole. Le coût de l'excellence. Paris: Seuil, 1991.

GREGÓRIO, José Renato Bez de. Política de pessoal docente do governo Lula: uma análise do REUNI e seus desdobramentos. 2011 . 269f. Dissertação (Mestrado em Educação) - Programa de Pós-Graduação em Educação, Universidade Federal Fluminense, Niterói, 2011.

LEDA, Denise Bessa; COSTA, Gleiciane Mendes; CORDEIRO, Neylla Cristhina Pereira. Reestruturação e expansão da educação superior: "A política é de você dar uma precarizada no trabalho docente". In: SEMINÁRIO NACIONAL UNIVERSITAS/Br, 22; 2014, Natal. Anais... Natal: Universidade Federal do Rio Grande do Norte, 2014. 1 CD-ROM.

LIMA, Kátia Regina de Souza. Contra-reforma na educação superior: de FHC a Lula. São Paulo: Xamã, 2007.

172 MANCEBO, Deise. Subjetividade docente. In: OLIVEIRA, Dalila Andrade; DUARTE, Adriana Maria Cancella; VIEIRA, Lívia Maria Fraga. (Org.). Dicionário de trabalho, profissão e condição docente. Belo Horizonte: GESTRADO/FAE/UFMG, 2010.

MANCEBO, Deise. Trabalho docente: subjetividade, sobreimplicação e prazer. Psicologia: Reflexão \& Crítica, Porto Alegre, v. 20, p. 74-80, 2007.

VALE, Andréa Araujo do; MORAIS, Carla Christina Imenes de; ÁVILA, Sueli de Fatima Ourique de; MEIRELES, Priscila Andreza; MATTOS, Lidiane. $\bigcirc$ trabalho docente no EAD: o caso do CEDERJ - parte I. In: SEMINÁRIO NACIONAL UNIVERSITAS/Br, 22; 2014 , Natal. Anais... Natal: Universidade Federal do Rio Grande do Norte, 2014. 1 CD-ROM.

OMS. Organização Mundial da Saúde - CID 10. Classificação estatística internacional de doenças e problemas relacionados à saúde. 10. ed. São Paulo: Edusp, 2007.

PAULA, Ana Paula Paes de. Por uma nova gestão pública: limites e potencialidades da experiência contemporânea. Rio de Janeiro: Editora Fundação Getúlio Vargas, 2005.

RIBEIRO, Carla Vaz dos Santos; DANTAS, Rodrigo de Oliveira; SILVA, Samiris Costa da. Processo de reestruturação e expansão em uma IFES: repercussões no trabalho docente. In: SEMINÁRIO NACIONAL UNIVERSITAS/Br, 22; 2014 , Natal. Anais... Natal: Universidade Federal do Rio Grande do Norte, 2014. 1 CD-ROM. 
RODRIGUES, Viviane de Souza. O REUNI como estratégia da contra-reforma na educação superior. 2011 . 210 f. Dissertação (Mestrado em Educação) - Programa de Pós-Graduação em Educação, Universidade Federal Fluminense, Niterói, 2011.

SGUISSARDI, Valdemar; GOERGEN, Pedro; DIAS SOBRINHO, José; PINO, Ivany; PIOZZI, Patrizia; OLIVEIRA, Romualdo Portela de; CAMARGO, Elizabeth. Universidade: reforma e/ou rendição ao mercado? Mercantilização do conhecimento e deserção do Estado. Educação \& Sociedade, Campinas, v. 25, n. 88, p. 647-651, out. 2004. Disponível em: htttp:// www.cedes.unicamp.br. Acesso em: 24 abr. 2013.

SGUISSARDI, Valdemar. Universidade pública estatal: entre o público e o privado/mercantil. Educação \& Sociedade, Campinas, v. 26, n. 90, p. 191-222, 2005.

SGUISSARDI, Valdemar; SILVA JÚNIOR, João dos Reis. Trabalho intensificado nas federais: pós-graduação e produtivismo acadêmico. São Paulo: Xamã, 2009.

SILVA JÚNIOR, João dos Reis; SGUISSARDI, Valdemar; SILVA, Eduardo Pinto e. Trabalho intensificado na universidade pública brasileira. In: OLIVEIRA, João Ferreira de; CATANI, Afrânio Mendes; SILVA JÚNIOR, João dos Reis (Org.). Educação superior no Brasil: tempos de internacionalização. São Paulo: Xamã, 2010.

SILVA, Eduardo Pinto. Trabalho, saúde e subjetividade do professor na universidade pública em expansão: estranhamento, sofrimento e prazer. 2013. 167f. Relatório de Pesquisa (PósDoutorado em Políticas Públicas) - Programa de Pós-Graduação em Políticas Públicas e Formação Humana, Universidade do Estado do Rio de Janeiro, Rio de Janeiro, 2013.

SILVA JÚNIOR, João dos Reis. O trabalho do professor diante da expansão da pós-graduação em educação: o caso da região sudeste. 2014. 235f. Relatório Pesquisa (Pós-Doutorado em Educação) - Programa de Pós-Graduação em Educação da Universidade Federal de São Carlos, São Carlos, 2014.

SOUSA, Adriana Modesto de. O perfil do adoecimento docente na Universidade de Brasília de 2006 a 2011. 2013. 103f. Dissertação (Mestrado em Ciências da Saúde) - Programa de Pós-Graduação em Ciências da Saúde, Universidade de Brasília, Brasília, 2013. 
Profa Dra. Carla Vaz do Ribeiro dos Santos Universidade Federal do Maranhão

Departamento de Psicologia Grupo de Pesquisa "Sociedade contemporânea, mundo do trabalho e processos de subjetividade" Rede Universitas/Br Observatório da Educação "Políticas de Expansão da Educação Superior no Brasil" Email | carlavazribeiro@uol.com.br

Profa Dra. Denise Bessa Leda Universidade Federal do Maranhão Departamento de Psicologia

Grupo de Pesquisa "Sociedade contemporânea, mundo do trabalho e processos de subjetividade" Pesquisadora da Rede Universitas/Br Pesquisadora do Observatório da Educação "Políticas de Expansão da Educação Superior no Brasil" Email | deniseb|@uol.com.br

Prof. Dr. Eduardo Pinto e Silva Universidade Federal de São Carlos Departamento de Educação Grupo de Pesquisa "Núcleo de Estudos Trabalho, Saúde e Subjetividade" Pesquisador da Rede Universitas/Br Pesquisador do Observatório da Educação "Políiticas de Expansão da Educação Superior no Brasil" Email |dups@ig.com.br

Recebido 11 set. 2014 Aceito 9 dez. 2014 